\title{
Sistem Informasi Penjualan Sparepart Honda Pada CV Indah Sakti Rantauprapat Dengan Menggunakan Bahasa Pemrograman Visual Basic 6.0
}

\author{
Muhammad Bobbi Kurniawan Nasution ${ }^{1}$ \\ ${ }^{1}$ Universitas Al Washliyah Labuhanbatu, Rantauprapat, Indonesia
}

\begin{tabular}{|c|c|}
\hline \multicolumn{2}{|c|}{ Info Artikel } \\
\hline \multicolumn{2}{|c|}{ Article history: } \\
\hline \multicolumn{2}{|c|}{$\begin{array}{l}\text { Received: } 21122018 \\
\text { Revised: } 13012019 \\
\text { Accepted: } 28012019\end{array}$} \\
\hline \multicolumn{2}{|c|}{ Kata Kunci: } \\
\hline $\begin{array}{l}\text { Perusahaan } \\
\text { Sparepart }\end{array}$ & Penjualan \\
\hline
\end{tabular}

Penulis Korespondensi:

\begin{abstract}
At present, the level of competition in the business world in Indonesia is very tight, because every company is always trying to increase market share and reach new customers. The company must be able to determine the right marketing strategy so that its business can survive and win the competition, so that the goals of the company can be achieved. In the process of selling spare parts for Honda CV products. Indah Sakti Rantauprapat, so far it is still manual, and there are still many shortcomings in inputting sales data and customer data, so marketing activities are used as a benchmark for problems by each company.
\end{abstract}

\begin{abstract}
Abstrak
Pada saat ini tingkat persaingan dunia usaha di Indonesia sangat ketat, karena setiap perusahaan senantiasa berusaha untuk dapat meningkatkan pangsa pasar dan meraih konsumen baru. Perusahaan harus dapat menentukan strategi pemasaran yang tepat agar usahanya dapat bertahan dan memenangi persaingan, sehingga tujuan dari perusahaan tersebut dapat tercapai. Dalam proses penjualan sparepart produk Honda CV. Indah Sakti Rantauprapat, selama ini masih manual, san masih banyak kekurangan dalam melakukan input data penjualan dan data pelanggan, maka kegiatan pemasaran dijadikan tolak ukur permasalahan oleh setiap perusahaan.
\end{abstract}

\section{PENDAHULUAN}

Tingkat persaingan dunia usaha di Indonesia sangat ketat, karena setiap perusahaan senantiasa berusaha untuk dapat meningkatkan pangsa pasar dan meraih konsumen baru. Perusahaan harus dapat menentukan strategi pemasaran yang tepat agar usahanya dapat bertahan dan memenangi persaingan, [1] sehingga tujuan dari perusahaan tersebut dapat tercapai. Pada dasarnya semakin banyak pesaing maka semakin banyak pula pilihan bagi pelanggan untuk dapat memilih produk yang sesuai dengan harapannya. Sehingga konsekuensi dari perubahan tersebut adalah pelanggan menjadi lebih cermat dan pintar menghadapi setiap produk yang diluncurkan.[2]

Tidak terlepas dari masalah yang ada di perusahaan CV. Indah Sakti, pada saat kondisi penjualan ramai dengan keterbatasan jumlah karyawan membuat transaksi penjualan tidak bisa dilakukan dengan efisien, pelanggan harus menunggu lama untuk layanan informasi barang yang dibutuhkan.[3] Lamanya layanan informasi barang dikarenakan dalam mencari informasi data barang masih menggunakan arsip-arsip dan dalam mencari barang admin harus melihat langsung ke ruangan suku cadang sehingga dikhawatirkan konsumen bisa merasa kecewa.[4]

\section{LANDASAN TIORI}

\subsection{Internet}

Secara sederhana sistem dapat diartikan sebagai suatu kumpulan atau himpunan dari unsur, komponen, atau variabel yang terorganisasi, saling berinteraksi, saling tergantung satu sama lain dan terpadu.[5] 
Menurut Tata Sutabri, (2012:13-14) Model umum sebuah sistem terdiri dari input, proses, dan output. Hal ini merupakan konsep sebuah sistem yang sangat sederhana mengingat sebuah sistem dapat mempunyai beberapa masukan dan keluaran sekaligus. Selain itu sebuah sistem juga memiliki karakteristik atau sifat-sitat tertentu, yang mencirikan bahwa hal tersebut bisa dikatakan sebagai suatu sistem.[6]

\subsubsection{Informasi}

Informasi adalah data yang telah diklasifikasikan atau diolah atau dipresentasikan untuk digunakan dalam proses pengambilan keputusan. Tata Sutabri, (2012 : 22-25).[7] Seperti yang telah dijelaskan tentang pengertian informasi, kualitas juga sangat diperlukan untuk sebuah informasi. Kualitas dari suatu informasi tergantung dari 3 (tiga) hal, yaitu informasi harus akurat, tepat waktu, dan relevan. Tata Sutabri, (2012 : 33 34). [8]

\subsubsection{Penjualan}

Tujuan perusahaan untuk memperoleh laba dari hasil penjualan merupakan hal penting agar perusahaan mampu bertahan menghadapi persaingan pasar yang semakin ketat.[9]dalam jurnal yang ditulis oleh Trimanto S. Wardoyo dan Luthfi Adriyanto,2011) mendefinisikan penjualan sebagai berikut: "Penjualan adalah suatu persetujuan yang menetapkan bahwa penjualan memindahkan milik kepada pembeli untuk sejumlah uang yang disebut harga.’[10]

\subsubsection{Basis Data}

Data merupakan bentuk mentah yang belum dapat bercerita banyak sehingga perlu diolah lebih lanjut. Tata Sutabri, (2012: 25).[11]

\subsubsection{Visual Basic}

Bahasa pemrograman Visual Basic merupakan bahasa pemrograman utama dari perusahaan Microsoft Inc yang paling sukses hingga dua belas tahun. Bahasa pemrograrnan ini menjadi contoh semua bahasa pemrograman RAD. Hingga tahun ini, kepopuleran bahasa pemrograman Visual Basic 6.0 masih bertahan kuat karena kemudahan.[12]

\section{METODOLOGI PENELITIAN}

\subsection{Tempat dan Waktu Penelitian}

CV. Indah Sakti berada di kawasan Rantauprapat dengan alamat Jl. Jend. A. Yani 74 ABC, dan sekarang sudah memiliki cabang di berbagai daerah, seperti pada saat sekarang ini untuk cabang yang berlokasi terletak di daerah kota Aeknabara, Jl.Ahmad Yani 52 AB Kab. Labuhan Batu propinsi sumatera utara. Sedangkan waktu penelitian, penulis melakukan penelitian mulai dari jam kerja yaitu pukul 10.00 wib sampai dengan selesai.

\subsubsection{Teknis Penelitian Alat Bahan dan Proses}

Penelitian ini menggunakan alat penelitian berupa perangkat keras dan perangkat lunak, yaitu:

1. Perangkat Keras
a. Processor Intel Pentium Processor P6100,
b. Besar memori RAM 1 GB DDR3,
c. Kapasitas Harddisk 320 GB,
d. Monitor dengan resolusi 1024 x 768 px,
e. Perangkat mouse dan keyboard standar.

2. Perangkat lunak
a. Sistem operasi Windows XP Service Pack 3,
b. Microsoft Access sebagai database,
c. Microsoft Visual Basic 6.0 sebagai rancangan desain aplikasi.
d. Crystall Report 8.5 sebagai laporan data. 


\section{HASIL DAN PEMBAHASAN}

\subsection{Software Implementasi}

\subsubsection{Maukkan (Input) Sistem}

\section{a. Input Menu Utama}

Menu utama awal mulainya melakukan input data yang berupa barang, pelanggan dan transaksi, seperti pada gambar dibawah :

\section{Gambar 4.1. Menu}

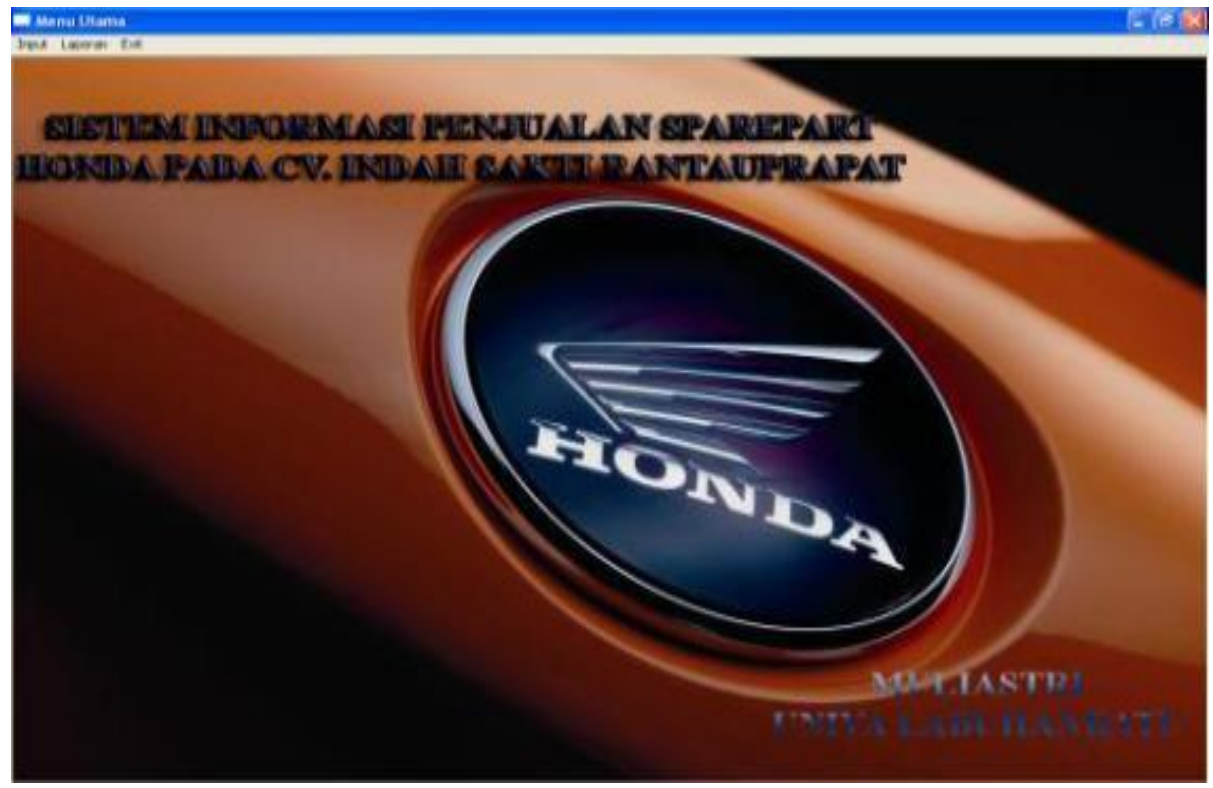

utama b. Input Menu Barang

Sedangkan pada menu barang, admin akan melakukan penginputan data barang, berupa jumlah barang yang ada dan disertai stock barang, seperti pada gambar dibawah ini :

\section{Gambar 4.2. Menu Data Barang}

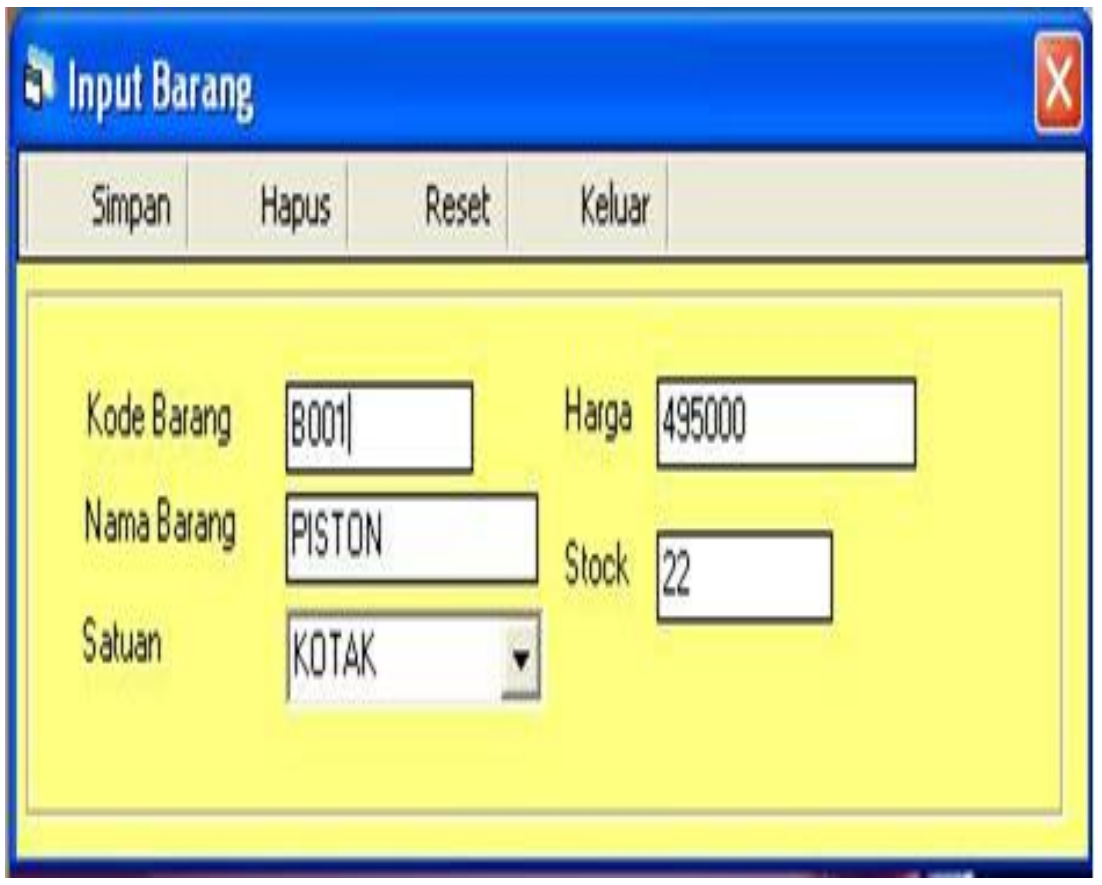


c. Input Menu Data Pelanggan

Sedangkan data pelanggan admin diwajibkan untuk melakukan penginputan dalam melakukan pendataan pelanggan yang sudah diisi, seperti pada gambar dibawah :

\section{Gambar 4.3. Menu Data}

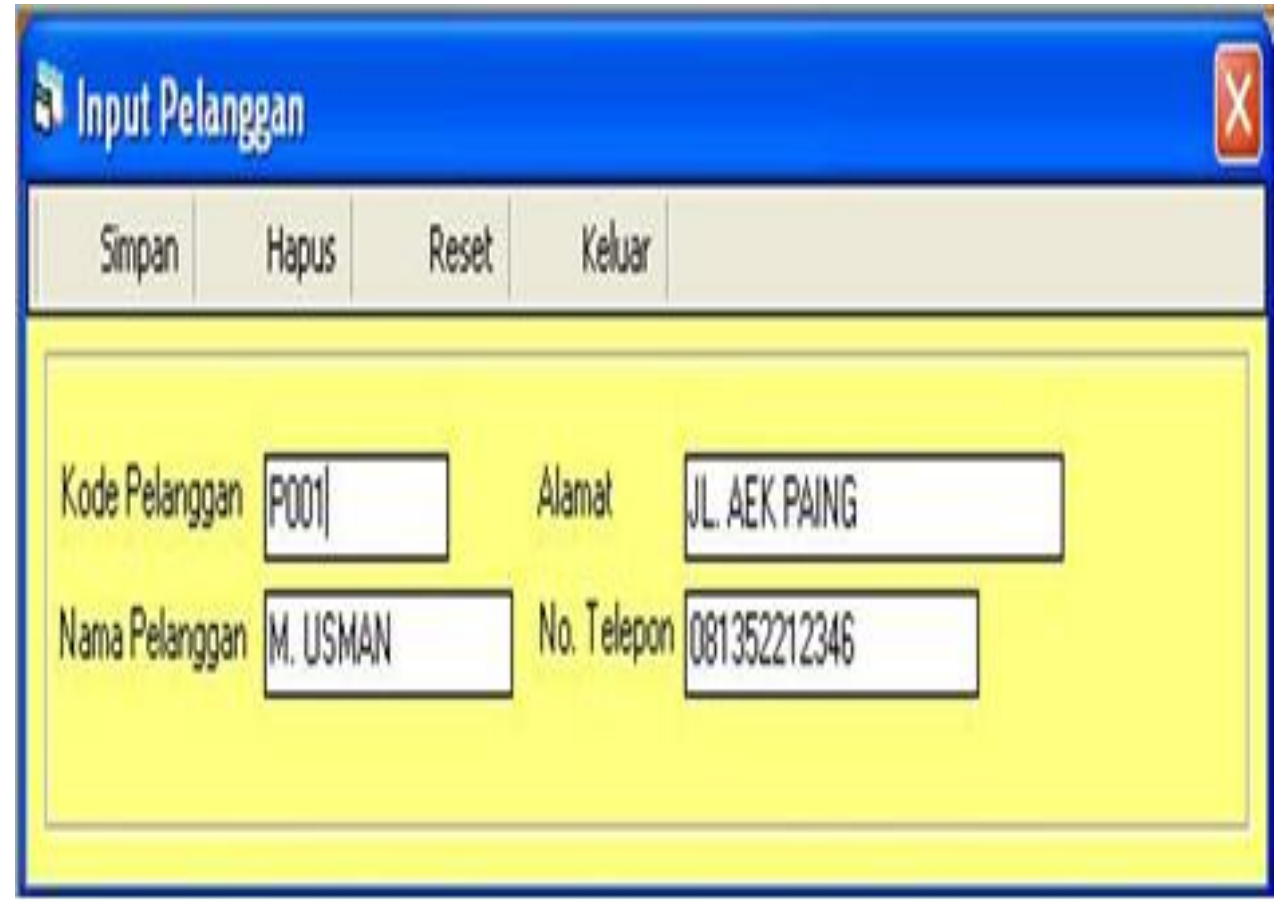

Pelanggan d. Input Menu Transaksi

Dalam pembahasan menu transaksi ini, admin sudah melakukan penginputan seperti pada gambar diatas, dan selanjutnya admin akan melakukan penginputan transaksi seperti pada gambar dibawah ini :

\section{Gambar 4.4. Menu Transaksi}

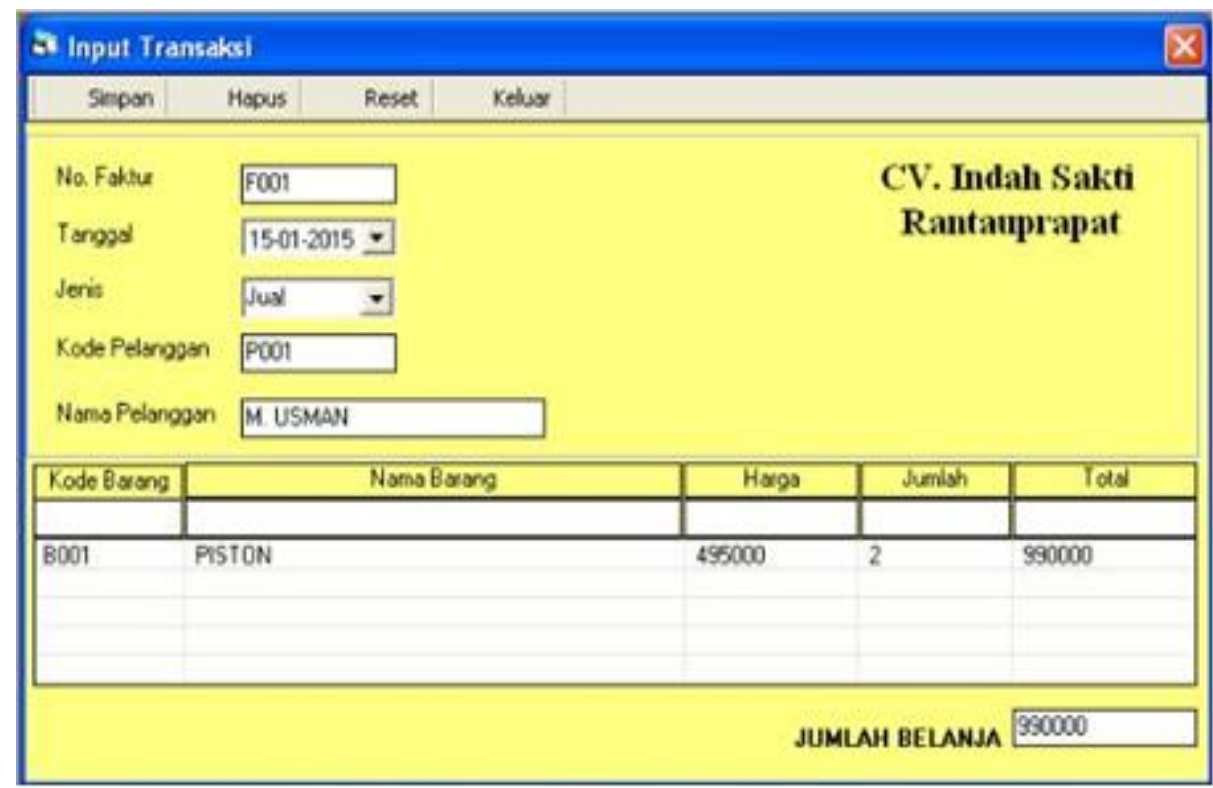




\subsubsection{Keluaran (Output) Sistem}

1. Menu Laporan Barang

Menu laporan barang yaitu berupa laporan barang yang sudah di inputkan, seperti pada gambar dibawah ini :

\section{Gambar 4.5. Menu Laporan Barang}

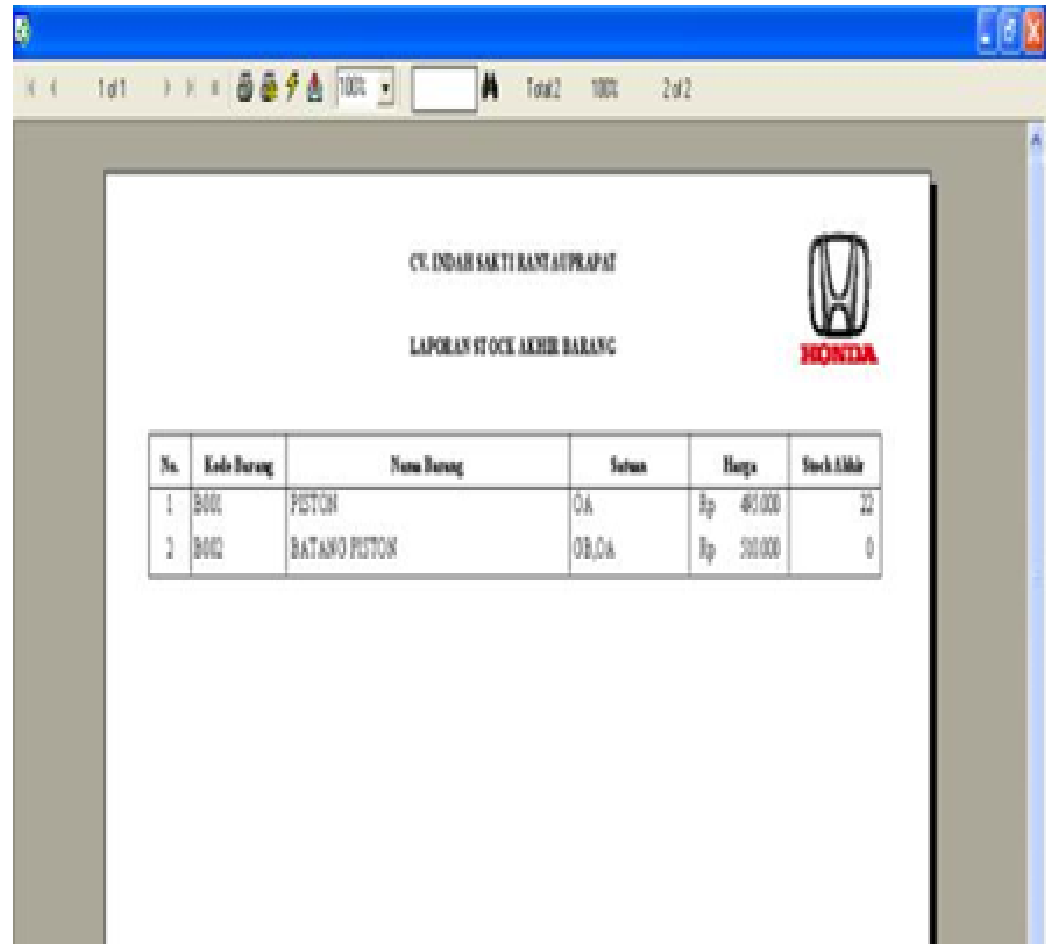

2. Menu Laporan Pelanggan

Menu laporan pelanggan yaitu berupa laporan pelanggan yang sudah di inputkan, seperti pada gambar dibawah ini :

Gambar 4.6. Menu Laporan Pelanggan

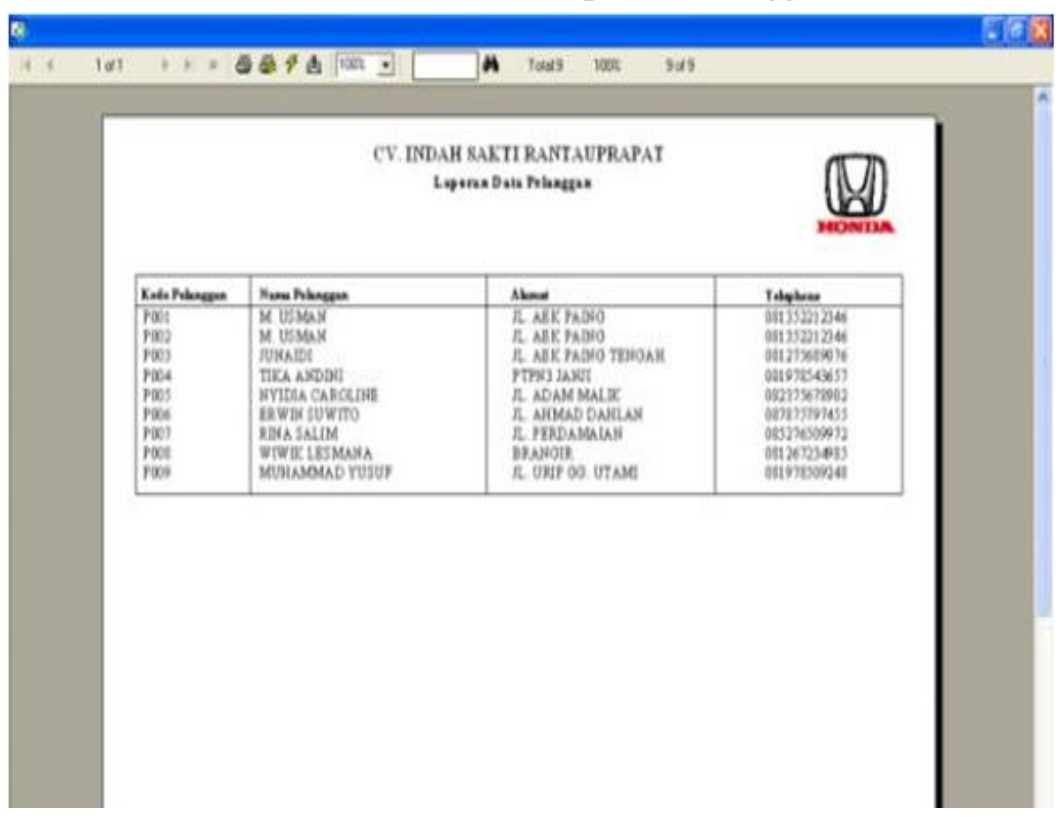


3. Menu Laporan Transaksi

Menu laporan transaksi yaitu berupa laporan rekap yang sudah di inputkan, seperti pada gambar dibawah ini

Gambar 4.7. Menu Laporan Transaksi

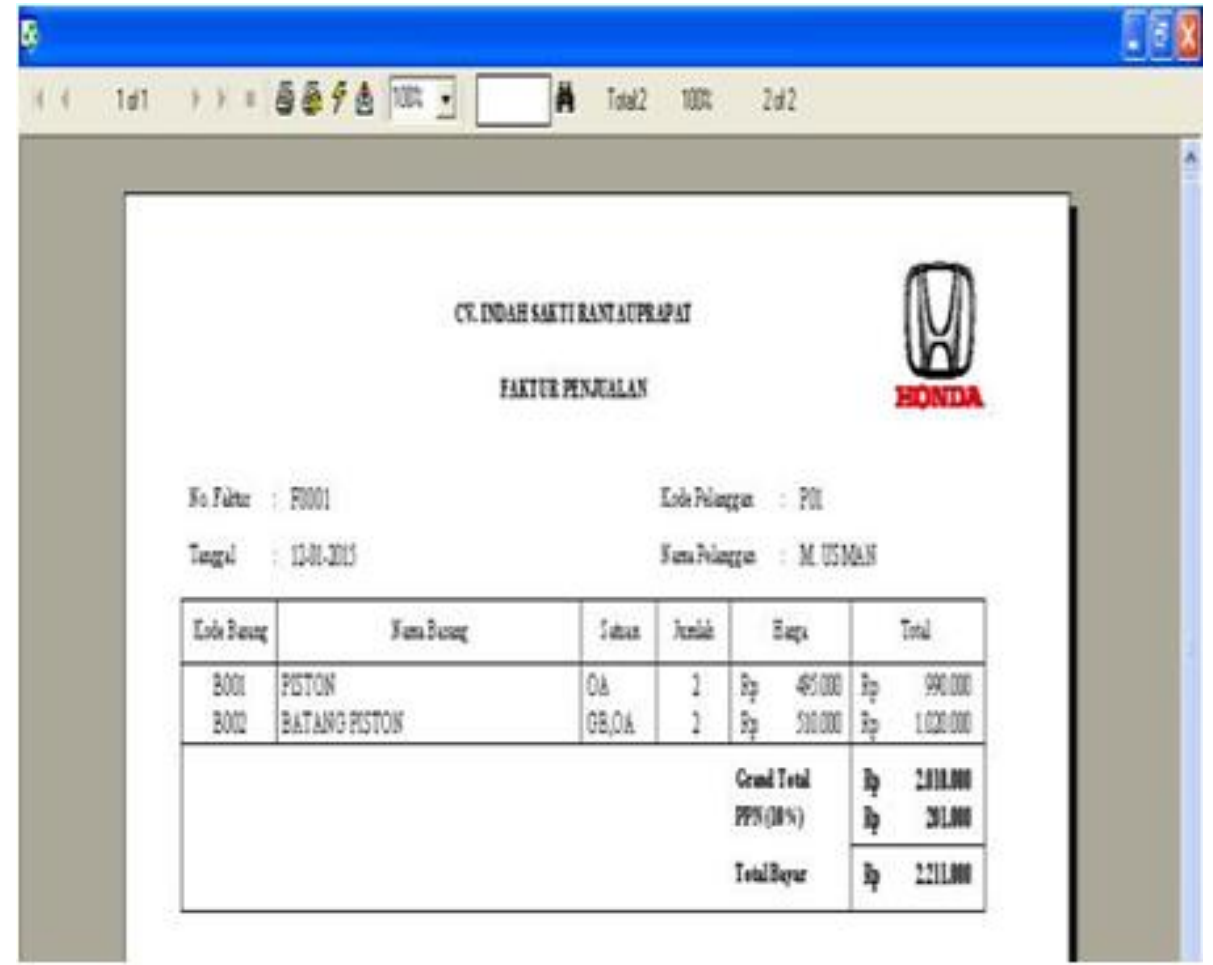

\section{KESIMPULAN DAN SARAN}

\subsection{Kesimpulan}

Setelah melakukan analisis, perancangan, dan pengujian, maka dapat diperoleh beberapa kesimpulan, antara lain :

1. Sistem informasi penjualan sparepart pada CV. Indah Sakti ini dapat melakukan penyimpanan data lewat database.

2. Sistem informasi penjualan cukup membantu dalam melakukan penjualan sparepart pada perusahaan CV. Indah Sakti Rantauprapat.

3. Sistem informasi penjualan pada CV. Indah Sakti ini menghasilkan informasi identifikasi yang cukup akurat.

\subsection{Saran}

Agar sistem penjualan sparepart ini kedepannya lebih baik, maka yang dapat disarankan adalah :

1. Mengingat besarnya pengetahuan yang berkaitan dengan software-software komputer, maka ruang lingkup sistem ini dalam melakukan identifikasi suatu penjualan dapat dikembangkan menjadi lebih luas dan lebih kompleks.

2. Memperbaiki dan memperindah tampilan antarmuka untuk menyajikan kenyamanan penggunaan oleh user.

3. Menyajikan solusi dalam hal penjualan yang lebih detil dengan langkah-langkah yang rinci dan disertai dengan animasi gambar. 


\section{REFERENSI}

[1] F. Edi, P. T. Informatika, and F. U. A. Labuhanbatu, "UNET | Jurnal Ilmiah Teknik Informatika LPPM Universitas Al Washliyah Labuhanbatu UNET | Jurnal Ilmiah Teknik Informatika ISSN . 2460-3694, Vol . 2 No . 1 Februari 2018," vol. 2, no. 1, pp. 2-5, 2018.

[2] D. I. G. H. Wirhan Fahrozi, Samsir, "Penerapan E-Commerce Pada Toko Bunga Underwear," J. Tek. Inform., vol. 04, no. 01, pp. 1-6, 2020.

[3] S. Samsir, S. Suparno, and M. Giatman, "Predicting the loan risk towards new customer applying data mining using nearest neighbor algorithm," IOP Conf. Ser. Mater. Sci. Eng., vol. 830, no. 3, 2020, doi: 10.1088/1757899X/830/3/032004.

[4] R. A. Purba, S. Samsir, M. Siddik, S. Sondang, and M. F. Nasir, "The optimalization of backpropagation neural networks to simplify decision making," IOP Conf. Ser. Mater. Sci. Eng., vol. 830, no. 2, 2020, doi: 10.1088/1757-899X/830/2/022091.

[5] W. Fahrozi, P. T. Informatika, T. Informatika, F. U. A. Labuhanbatu, T. Mulia, and K. Medan, "U-NET : Jurnal Teknik Informatika LPPM - Universitas Al Washliyah Labuhanbatu 23 | P a g e U-NET : Jurnal Teknik Informatika Sebagai langkah awal yang dilakukan supaya dapat mengetahui gambaran permasalahan yang dihadapi dalam menentukan rasa yam serama a," vol. 3, no. 5, pp. 23-27, 2019.

[6] Samsir, "Klasifikasi Penyakit Tenggorokan Hidung Telinga ( THT ) Menggunakan Jaringan Syaraf Tiruan Dengan Metode Learning Vektor Quantization ( THT ) Di RSUD Rantauprapat Labuhanbatu Klasifikasi penyakit Tenggorokan Hidung Telinga ( THT ) Menggunakan,” vol. 05, no. 01, pp. 38-47, 2019.

[7] D. Indra et al., "SPK Untuk Pemilihan Kepala Sekolah Menggunakan Metode Saw dan Profile Matching," vol. 4, no. 1, pp. 7-12, 2020 .

[8] P. T. Informatika and F. U. A. Labuhanbatu, "U-NET : Jurnal Teknik Informatika LPPM - Universitas Al Washliyah Labuhanbatu 18 |P a g e U-NET : Jurnal Teknik Informatika Sebagai langkah awal yang dilakukan supaya dapat mengetahui gambaran permasalahan yang dihadapi oleh bagian kesiswaan adalah denga," vol. 3 , no. 4, pp. 18-22, 2019.

[9] M. Siddik and S. Samsir, "Rancang Bangun Sistem Informasi Pos (Point of Sale) Untuk Kasir Menggunakan Konsep Bahasa Pemrograman Orientasi Objek,” JOISIE (Journal Inf. Syst. Informatics Eng., vol. 4, no. 1, p. 43, 2020, doi: 10.35145/joisie.v4i1.607.

[10] Samsir and Syaiful Zuhri Harahap, "Application Design Resume Medical By Using Microsoft Visual Basic. Net 2010 At the Health Center Appointments," Int. J. Sci. Technol. Manag., vol. 1, no. 1, pp. 14-20, 2020, doi: 10.46729/ijstm.v1i1.5.

[11] M. V. B. Net, "PADA TOKO URIP MOTOR,” no. September, pp. 1-6, 2020.

[12] Samsir, D. I. G. Hts, and S. Z. Harahap, "SPK Untuk Pemilihan Kepala Sekolah Menggunakan Metode Saw dan Profile Matching,” U-NET J. Tek. Inform., 2020. 